\title{
Discussion Paper No. 13-102 \\ Which Indicators of Absorptive Capacity Enhance Import-induced South-North Convergence in Labor Intensities?
}

Michael Hübler and Alexander Glas

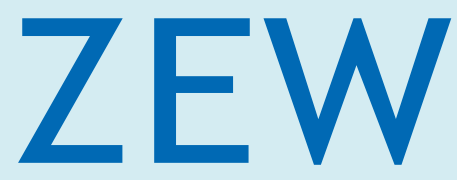

Zentrum für Europäische Wirtschaftsforschung $\mathrm{GmbH}$

Centre for European

Economic Research 
Discussion Paper No. 13-102

\section{Which Indicators of Absorptive Capacity Enhance Import-induced South-North Convergence in Labor Intensities?}

Michael Hübler and Alexander Glas

Download this ZEW Discussion Paper from our ftp server:

http://ftp.zew.de/pub/zew-docs/dp/dp13105.pdf

Die Discussion Papers dienen einer möglichst schnellen Verbreitung von neueren Forschungsarbeiten des ZEW. Die Beiträge liegen in alleiniger Verantwortung der Autoren und stellen nicht notwendigerweise die Meinung des ZEW dar.

Discussion Papers are intended to make results of ZEW research promptly available to other economists in order to encourage discussion and suggestions for revisions. The authors are solely responsible for the contents which do not necessarily represent the opinion of the ZEW. 


\title{
Which Indicators of Absorptive Capacity Enhance Import-induced South-North Convergence in Labor Intensities?
}

\author{
Michael Hübler* \\ Alexander Glas ${ }^{\dagger}$
}

November 20, 2013

\begin{abstract}
We hypothesize that North-South trade is associated with knowledge spillovers that create labor productivity gains depending on various determinants of Southern absorptive capacity. We use the novel World Input-Output Database (WIOD) that provides bilateral and bisectoral panel data for 39 countries and 35 sectors for 1995-2009. We examine growth in relative South-North labor intensities (South-North convergence) for 31 industrialized source and eight emerging recipient countries. We find robust evidence that the following measures of absorptive capacity (ordered by magnitude of the estimated coefficients) interact with imports so that relative labor intensity is reduced: economic freedom and political and civil rights, services, skills, scientific publications and patents as well as telephone and internet access. GMM and GLS estimations corroborate the results. Policies that support various of the identified determinants of absorptive capacity are more promising than policies that select only one. Elevating the absorptive capacity of emerging economies to the maximum level in the world would halve the South-North gap in labor intensities within a couple of decades if it were solely achieved through the trade channel.
\end{abstract}

JEL classifications: C23, F18, F21, O13, O33, O47, Q43

Keywords: absorptive capacity, labor intensity, trade, South-North, convergence

${ }^{*}$ Corresponding author, email: michael-huebler@web.de, tel: +49-621-1235-340, fax: +49-621-1235226, Centre for European Economic Research (ZEW), P.O. Box 103443, 68034 Mannheim, Germany; Leibniz University Hanover, Germany.

${ }^{\dagger}$ Email: alexander.glas@awi.uni-heidelberg.de, University of Heidelberg, Germany. 


\section{Introduction}

This is the first study that explores the role of country characteristics in absorbing foreign knowledge through imports in a systematic, extended way. We follow Abramowitz's (1986) perspective of South-North convergence in productivity levels and the role of social capability as a prerequisite for absorbing foreign knowledge. We define all recipient country characteristics that are relevant for absorbing foreign knowledge via imports as determinants of the absorptive capacity. Our analysis is more systematic than the literature so far because it includes more determinants of absorptive capacity and utilizes a novel bilateral and bisectoral trade data set.

International technology transfer (or technology diffusion or technology spillovers) is often seen as a key for promoting economic growth and development. Firms in industrialized countries are engaged in research and development $(R \& D)$ resulting in advanced (technological) knowledge and advanced (efficient) technologies. These technologies can be transferred to developing and emerging countries, particularly embodied in investment goods. Firms in developing countries can apply these technologies and learn how to use, replicate and further develop them. This implies technology diffusion from North (in our sample industrialized source countries, mostly belonging to the Organisation for Economic Co-operation and Development, OECD, or the European Union, EU) to South (in our sample emerging, non-OECD recipient countries) and within the South. Emerging economies are in this context of greater interest than less developed countries, because they are intensively engaged in trade and $\mathrm{R} \& \mathrm{D}$. On the one hand, technology transfer is desirable from the viewpoint of governments that aim to support international trade, economic growth and development. It is also desirable from the viewpoint of firms in recipient emerging countries that still lack in technological capability: technology diffusion amplifies productivity and thus output and market share. On the other hand, firms in industrialized countries are reluctant to provide their technological knowledge to firms in low-wage countries because they fear intensified competition.

The central question is: in how far and for what reasons are emerging economies able to absorb imported foreign technologies? To what extent are they able to assimilate, use and possibly further develop technologies received through investment goods imports. This aspect is often referred to as absorptive capacity. Thus, the question we address in this paper reads: what creates absorptive capacity? An answer to this question would help policy makers design policies that support international technology diffusion, boost productivity and strengthen economic development. It would also confirm or reject firms' 
competitiveness concerns. We hypothesize that the following indicators determine the absorptive capacity of developing recipient countries: (1) Freedom of economic activity and political and civil rights, such as property rights and intellectual property rights, because they secure and spur people's market activities including technology-related activities. (2) Education and skills because they enable people to understand, use and develop technical products. (3) Access to telecommunication and internet because they enable and ease the access to and spread of information. (4) Basic research represented by journal publications and applied research represented by patents because they enhance the ability to understand and develop technologies based on existing knowledge. Moreover, the ability of firms to exploit and keep technological advantages is represented by patents and trademarks. (5) Structure of the economy in terms of the relative size and hence the importance of the service sector and the high-tech industry. The high-tech industry is supposed to adopt advanced technologies above-average. The service sector is not only supposed to utilize advanced technologies, but also to provide services such as consulting and maintenance that are vital to run advanced technologies.

Surprisingly, such a portfolio of potential determinants of absorptive capacity (beyond education or human capital) and its interaction with imports (or FDI) have hardly been addressed by the literature (less systematic studies on institutional factors are CrespoCuaresma et al., 2008, Coe et al., 2009, and Perkins and Neumayer, 2012; for more details see section 2). ${ }^{1}$ We fill this gap by using the very large and comprehensive new data set WIOD (World Input-Output Data, cf. Dietzenbacher et al., 2013) that provides bilateral and bisectoral trade data for 39 countries and 35 sectors for 1995-2009. Within this data set, we define 31 industrialized countries as Northern countries, i.e. sources of investment goods and embodied knowledge, and the eight remaining emerging countries Brazil, Bulgaria, China, India, Indonesia, Mexico, Romania, and Russia as Southern recipient economies of goods and knowledge. We do not only include the determinants of absorptive capacity as single regressors but let them also interact with the country-specific import rate of investment goods. This means, we focus on the determinants of absorptive capacity with respect to technology spillovers via imports. We measure their impact on the growth rate of the relative (South-North) labor intensity of production. We utilize standard and GMM (Generalized Method of Moments) fixed-effects estimation techniques as well as GLS (Generalized Least Squares) estimation techniques in robustness checks.

\footnotetext{
${ }^{1}$ Perkins and Neumayer (2012): "We are aware of no existing quantitative research which has examined the influence of the above mediating domestic attributes - i.e. domestic efficiency and social capabilities over the degree of $\mathrm{CO}_{2}$-efficiency spillovers."
} 
Like Mazumdar (2001), we contrast imported investment goods with domestically produced investment goods. Different to Mazumdar, we extend the scope of imports beyond machinery to various types of investment goods, and we focus on emerging economies instead of least developed countries.

Our results show that (ordered by the magnitude of the estimated coefficients) economic freedom and political and civil rights, services, skills, scientific publications and patents, telephone and internet access, and (though not significant in the GMM estimation) the high-tech industry share interact with the import rate of investment goods in such a way that the relative labor intensity of Souther emerging economies declines. This means, the labor intensity of a Southern country declines faster than the labor intensity of (a source sector in) a Northern country. This in turn implies South-North convergence in labor productivity (the inverse of labor intensity). It confirms our hypothesis that these indicators represent determinants of the absorptive capacity. The interaction of tertiary education with imports unexpectedly shows no significant effect. This indicates that the effect of education on knowledge diffusion, commonly conjectured and confirmed by the literature, is direct and not necessarily linked to investment good imports. The interaction of the trademark rate increases the relative labor intensity (not significant in the GMM estimation). This indicates that trademarks may be associated with outsourcing of labor-intensive activities to developing countries. Different to Mazumdar (2001), we do not identify a clear-cut, robust distinction between imported and domestically produced investment goods regarding their effect on relative labor intensity in this study. Notably, all these interaction effects have small magnitudes.

The paper proceeds as follows: section 2 positions our paper in the literature. Section 3 sets up the econometric model. Section 4 describes the data. Section 5 describes and discusses the regression results. Section 6 discusses robustness checks. Section 7 carries out a policy experiment drawing upon the estimated results. Section 8 concludes by deriving policy implications.

\section{Literature}

This section positions our paper in the literature. Our paper relates to the literature that estimates international technology spillovers via trade and FDI (foreign direct investment) and to the literature that assesses the impact of human capital on growth.

A large econometric literature strand examines the productivity effects of international technology spillovers on recipient countries via trade and FDI and finds mixed results (for 
overviews see Saggi, 2002; Keller, 2004; Hoekman and Javorcik, 2006). Whereas Coe and Helpman (1995) utilize data for OECD countries and Israel, Coe et al. (1997) utilize data for industrialized and a large number of developing countries. Both studies emphasize that substantial international R\&D spillovers exist, in the latter study from North to South. Though, the focus of our endeavor is not the detection of international technology spillovers. It is the detection of accompanying factors that ease trade-related technology spillovers. In this respect, we go back to classical theory: the Nelson and Phelps (1966) theory assumes that educational attainment and a larger distance between the technology in practice and the technology frontier enhance technology diffusion. Findlay (1978) adds FDI as the transmitter of productivity gains to this framework.

Inspired by the classical theory, a number of econometric studies pay attention to the distance to the technology frontier (for example, Griffith et al., 2004, and Benhabib and Spiegel, 2005, for disembodied technology spillovers; Girma, 2005, for FDI-related spillovers at the industry level). The results of these studies are, however, ambiguous with respect to the question whether technology diffusion in- or decreases in the distance to the technology frontier. Furthermore, a fruitful econometric literature strand identifies a positive impact of human capital (education) on productivity growth (for example, Eaton and Kortum, 1996; Griffith et al., 2004; Benhabib and Spiegel, 2005). This result is, however, not undisputed. Pritchett (2001), for example, finds that human capital growth reduces productivity. Though, this literature strand mostly explores the direct, disembodied effect of human capital on growth and does not investigate the trade-related, embodied effect. An exception is the empirical study by Falvey et al. (2007). They consider imports of machinery and transport equipment as the productivity spillover transmission channel, and they consider schooling as the single determinant of absorptive capacity. Their "threshold analysis suggests that recipient countries benefit from trade-related knowledge spillovers at all education levels, but those with the highest levels of education benefit more." Another example is the study by Lai et al. (2006). Their results indicate that human capital enhances technology spillovers to China via imports and FDI. Other studies find that human capital elevates FDI-related productivity spillovers, too (Borensztein et al., 1998; Ciruelos and Wang, 2005, both utilize schooling). Yet, our analysis deals with imports of investment goods, not with FDI. One recent import-related study is Carraro and De Cian (2013). Yet this study treats education as a control variable, not as a trade-related interaction term as we do.

Although it is common to take human capital (education) as a determinant of economic 
growth in general and of international technology spillovers in particular into account, only few econometric studies consider further institutional determinants. Building on Coe and Helpman (1995) and Coe et al. (1997), Coe et al. (2009) show that the ease of doing business, tertiary education, patent protection and legal systems based on German or English law improve international R\&D spillovers. Building on Coe and Helpman (1995) and Coe et al. (1997), Crespo-Cuaresma et al. (2008) "find that countries with lower levels of product market regulation, employment protection and lower barriers to entrepreneurship benefit to a greater extent from foreign R\&D." Our study extends on this work by applying a new global data set and systematically including a large number of additional determinants. Drawing upon patent data, Dechezleprêtre et al. (2013) demonstrate that existing technological capability can hinder the absorption of foreign climate-friendly technologies. The intuition is that existing domestic technologies can not only complement, but also substitute foreign technologies. Our results affirm this ambiguity with respect to the high-tech industry share. Furthermore, Perkins and Neumayer (2012) examine the interaction of education as well as institutional quality with imports and FDI. To this end, Perkins and Neumayer (2012) utilize education measured as "the average number of years of schooling received by the population aged 25 and above" and a constructed indicator "that measures the unweighed mean of a country's value on bureaucratic quality, rule of law and the absence of corruption, as published by the International Country Risk Guide" (ICRG published by The PRS Group, 2009²). They find that higher institutional quality supports FDI-weighted productivity spillovers, whereas education supports import-weighted spillovers. They examine, however, the impact on $\mathrm{CO}_{2}$ intensity, not labor productivity as we do. Augier et al. (2013) represent absorptive capacity with respect to imports by the high-skilled labor share and $R \& D$ expenditures. They highlight that skill intensity clearly improves total factor productivity gains from importing. Different to them, we do not examine Spanish firms, but emerging economies. Perkins and Neumayer (2012) as well as Augier et al. (2013) restrict their analysis to two indicators of absorptive capacity. We extend this scope by including a variety of indicators.

\section{Model}

This section sets up our econometric model. The model follows Abramowitz's (1986) view of South-North convergence in productivity levels and the role of social capability as a

\footnotetext{
${ }^{2}$ http://www.prsgroup.com/prsgroup_shoppingcart/pc-39-7-international-country-risk-guide-icrg. aspx
} 
prerequisite for absorbing foreign knowledge. It does not explicitly model faster catching up of backward countries. ${ }^{3}$ We start with a Cobb-Douglas specification that describes relative, i.e. South-North, labor intensity:

$$
r l_{s r j t+1}=r l_{s r j t} \cdot e^{\varsigma+\sigma_{s r j}+\theta_{t}} \cdot i m_{s r j(t-3)}^{\beta_{I M}} \cdot d i_{r(t-3)}^{\beta_{D I}} \cdot x_{r(t-3)}^{\beta_{X}}
$$

$r l$ signifies the relative labor intensity. $s$ denotes a source country, $r$ a recipient country, $j$ a source sector, and $t$ a time period (year). $r l$ is a function of itself with a one-period time lag. This implies that $r l$ follows a time path and that the following explanatory variables cause deviations from this time path. $\varsigma, \sigma_{s r j}$ and $\theta_{t}$ denote an overall constant exogenous driver, a source-country-, recipient-country- and source-sector-specific exogenous driver and a time-specific exogenous driver. im signifies the investment good import intensity, whereas $d i$ signifies the domestically produced investment good intensity. $\beta_{I M}$ and $\beta_{D I}$ are the corresponding exponents that measure their strength. The focus of this analysis is on $x$ and its exponent $\beta_{X}$, which represent recipient country characteristics that determine the technological absorptive capacity of a recipient country and its strength. At this stage, $x$ denotes the aggregate absorptive capacity. In the following, each variable will be explained in more detail.

The following steps will lead to the econometric model that we will estimate. We take the natural logarithm of Equation (1). We subtract $\log \left(r l_{s r j t}\right)$ and rewrite $d R L_{s r j t}=$ $d \log \left(r l_{s r j t}\right)=\log \left(r l_{s r j t+1}\right)-\log \left(r l_{s r j t}\right)$. Furthermore, we rewrite $I M=\log (i m)$ and $D I=\log (d i)$ for simplicity. We replace $x$ by a column vector $[X]$ that contains various determinants of the recipient country's absorptive capacity, in all cases in log-form. Accordingly, $\left[\beta_{X}\right]$ becomes a row vector that measures the strength of these particular determinants. We add an error term $\varepsilon_{s r j t}$ which captures deviations not explained by the model.

As a result, we obtain the econometric model. This model describes the growth rate of the relative labor intensity $d R L_{s r j t}$ driven by a change in the investment good import rate $I M$, a change in the domestic investment rate $D I$ and changes in various determinants of the absorptive capacity represented by the vector of variables $[X]$ :

$$
d R L_{s r j t}=\varsigma+\beta_{I M} \cdot I M_{s r j(t-3)}+\beta_{D I} \cdot D I_{r(t-3)}+\left[\beta_{X}\right] \cdot[X]_{r(t-3)}+\sigma_{s r j}+\theta_{t}+\varepsilon_{\text {srjt }}
$$

\footnotetext{
${ }^{3}$ This aspect has been extensively researched (cf. section 2 ), hence it is not the focus of this analysis. Additionally, our econometric experiments including technology gap terms for representing catching up and their interaction with other variables did not create meaningful significant results in our context.
} 
$s$ denotes source countries, i.e. 31 industrialized countries. ${ }^{4} r$ denotes recipient countries, i.e. eight emerging economies: Brazil, Bulgaria, China, India, Indonesia, Mexico, Romania and Russia. ${ }^{5} j$ denotes source country sectors. ${ }^{6}$

The dependent variable $d R L$ is the annual growth rate of relative labor intensity, i.e. the South-North ratio of labor intensity in $d \log$ form. ${ }^{7}$ Relative means, the economy-wide labor intensity in a recipient country $r$ is measured relative to the labor intensity in a source country's $s$ sector $j$. This model implies that a relative change in an explanatory variables, for example by ten percent, to a new level results in a change in the growth rate of relative labor intensity in each year, for example by 0.1 percentage points. This means, each explanatory variable has a permanent effect on annual growth. This implies that the heterogeneity of source sectors and hence of traded goods with respect to their importance for technology spillovers is taken into account. The relative South-North measurement also implies that we study South-North convergence versus divergence in labor intensities. We want to know whether the emerging economies in our sample are able to catch up to the industrialized countries in terms of productivity. Therein, labor intensity means labor input in working hours per output value in 1995-US-\$. If there is South-North convergence in labor intensity, $d R L$ will be negative. This specification takes into account that source sectors have different productivity levels. And productivity naturally differs across sectors due to sector-specific process technologies and other circumstances. We do not explain, however, why these differences between sectoral productivities exist, but whether and by how much they change, recalling that we look at $d R L$ in $d l o g$ form. If the South-North ratio stays constant, we will not observe a relevant change, no matter how small or large the South-North ratio is due to sector characteristics.

\footnotetext{
${ }^{4}$ Australia; Austria; Belgium; Canada; Cyprus; Czech Republic; Denmark; Estonia; Finland; France; Germany; Greece; Hungary; Ireland; Italy; Japan; Korea; Latvia; Lithuania; Luxembourg; Malta; Netherlands; Poland; Portugal; Slovak Republic; Slovenia; Spain; Sweden; Turkey; United Kingdom; United States of America.

${ }^{5}$ We leave out Taiwan which is in WIOD because of missing absorptive capacity data.

${ }^{6}$ Agriculture, Hunting, Forestry and Fishing; Mining and Quarrying; Food, Beverages and Tobacco; Textiles and Textile Products; Leather, Leather and Footwear; Wood and Products of Wood and Cork; Pulp, Paper, Printing and Publishing; Coke, Refined Petroleum and Nuclear Fuel; Chemicals and Chemical Products; Rubber and Plastics; Other Non-Metallic Mineral; Basic Metals and Fabricated Metal; Machinery, Nec; Electrical and Optical Equipment; Transport Equipment; Manufacturing, Nec, Recycling; Electricity, Gas and Water Supply; Construction; Sale, Maintenance and Repair of Motor Vehicles and Motorcycles; Retail Sale of Fuel; Wholesale Trade and Commission Trade, Except of Motor Vehicles and Motorcycles; Retail Trade, Except of Motor Vehicles and Motorcycles; Repair of Household Goods; Hotels and Restaurants; Inland Transport; Water Transport; Air Transport; Other Supporting and Auxiliary Transport Activities; Activities of Travel Agencies; Post and Telecommunications; Financial Intermediation; Real Estate Activities; Renting of M\&Eq and Other Business Activities; Public Admin and Defence; Compulsory Social Security; Education; Health and Social Work; Other Community, Social and Personal Services; Private Households with Employed Persons.

${ }^{7} d R L_{\text {srjt }}=$ dlogrl $_{\text {srjt }}$ describes growth within period $t$ where $r l$ is labor input in working hours per output value in the recipient country relative to a source country sector. Source country sector and recipient country are connected via trade of an investment good.
} 
Imports from sectors $j$ are used for investment throughout recipient economies without distinguishing recipient sectors. This means, we take all types of traded goods into account that are fed into the economy-wide capital investment good in the recipient country. We focus on investment goods because they enter the productive capital stock and are supposed to embody advanced technologies that raise the productivity of the capital stock. Imports $I M$ are measured as the import value relative to the output value in $\log$ form. Thus $I M$ has no unit. $\beta_{I M}$ denotes the corresponding coefficient to be estimated. We expect $\beta_{I M}$ to be negative because this implies that the growth rate of the Southern labor intensity measured relative to the Northern one, i.e. $d R L$, declines in the import rate $I M$.

Besides imported investment goods, we also include domestically produced investment goods that are fed into the same economy-wide capital investment good as imported investment goods. We also measure domestic investment in $l o g$ intensity form, denoted by $D I$, measured relative to the output value. $D I$ has no unit either because numerator and denominator are measured in 1995-US-\$. The corresponding coefficient is $\beta_{D I}$. If imported investment goods embody advanced technologies, but domestically produced investment goods do not, $\beta_{I M}$ will be negative, but $\beta_{D I}$ will not necessarily be negative.

$\left[\beta_{X}\right]$ is a row vector to be estimated, and $[X]$ is a column vector that contains the following determinants of the technological absorptive capacity of recipient countries. They are all measured in logarithmic form so that the estimated coefficients will be comparable.

$H L$ is the high-skilled labor share, i.e. the $\log$ share of high-skilled labor working hours in all working hours. ${ }^{8}$ Higher skills of workers are commonly associated with higher education including a better technological understanding. This technological understanding is expected to ease the utilization, adoption, further development and imitation of new technologies. Without skilled workers, like engineers who are familiar with specific machinery and maintain the machinery, it is hardly possible to run advanced equipment successfully. Different to general measures of education or schooling, the high-skill labor share provides a more precise measure of the implementation and importance of education in the labor force. Notwithstanding, this indicator is related to the tertiary education rate that we also apply.

FH is the Freedom House index in log form. It has the characteristics 'not free' (value of 1 in the notation used in this paper), 'partially free' (value of 2) and 'free' (value of 3). This index is the average of two sub-indices: political rights and civil liberties. Both are measured on a scale of 1 to 7 , with 1 representing the highest degree of freedom and 7 the

\footnotetext{
${ }^{8}$ High-skilled means first and second stage of tertiary education (1997 ISCED levels 5 and 6).
} 
lowest. We expect that political rights and civil liberties accentuate economic freedom, i.e. the freedom of doing business including those in technology-oriented fields. This in turn would ease innovation and the adoption of new technologies.

$E F$ is the Economic Freedom index in $\log$ form. This index is the average of 10 subindices: business freedom, trade freedom, monetary freedom, government size/spending, fiscal freedom, property rights, investment freedom, financial freedom, freedom from corruption and labor freedom. Each of the sub-indices is measured on a scale of 0 to 100 with high numbers indicating higher degrees of freedom. Basically, the same argumentation as for the Freedom House index applies. The Economic Freedom index is, however, more detailed. More liberal investment and financial possibilities are expected to enhance investments in $\mathrm{R} \& \mathrm{D}$, technology adoption and imitation activities. Less corruption and better working conditions and choices may open opportunities for innovative profound work instead of keeping the status quo and exploiting workers with stultifying daily work.

$T E$ is the tertiary education rate, i.e. the $\log$ gross tertiary education enrollment rate in percent. As for example Griffith et al. (2004), we focus on tertiary education. As we are looking at trade-embodied knowledge spillovers, primary and secondary education seem to be less relevant for our analysis. Higher education that includes technological understanding is needed to apply and assimilate the advanced technologies that are embodied in investment good imports. Moreover, the tertiary education data have the advantage of being available for the whole sample. Different to the high-skilled labor indicator, the tertiary education rate leaves open how education translates into a share in actual working hours.

$I N$ is the internet rate, i.e. the $\log$ number of internet users per 100 people of the population. This indicator describes access to the global knowledge pool as well as to worldwide information exchange and communication. The global knowledge helps properly apply and understand imported equipment and embodied technologies. Information exchange and communication help to get connected, to exchange knowledge and ideas and thus to help each other and learn from each other.

$T P$ is the telephone rate, i.e. the $\log$ telephone lines per 100 people of the population. The argumentation follows that of the internet rate, yet on a less technologically advanced level. Due to insufficient data availability for our sample, the spread of mobile phones, which is of high importance in less developed countries, is not accounted for in our sample of emerging economies.

$S A$ is the scientific article rate, i.e. the $\log$ number of scientific and technical journal 
publications within a particular country per capita. This measure indicates the intensity of basic and to some extent applied research. The resulting existing knowledge eases the absorption of new knowledge by building on the profound knowledge base. R\&D expenditures as a measure for applied industrial research, on the contrary, are not available for our sample of emerging economies. This relates to the fact that $R \& D$ is mainly expedited by the leading OECD countries.

$P A$ is the patent rate, i.e. the $\log$ number of patent applications (by non-residents) in this country divided by the population of this country. Similar to scientific publications, patents characterize preexisting knowledge to build on. While R\&D expenditures as a measure for applied (industrial) research are not sufficiently available for our sample, patents data are available and represent applied industrial research. The perspective is not on residents' patent application abroad, which would hardly affect the absorptive capacity at home, in the emerging economy, but on patent applications within the emerging economy. They are supposed to characterize preexisting transferred knowledge.

$T M$ is the trademark rate, i.e. the log number of trademark applications per capita. Trademark applications are an even more applied, industry-oriented measure than patents. They imply that an established trademark exists that may encompass brand-specific technologies. The application of a trademark in an emerging economy might thus go along with the use of technologies that might create technology spillovers. Nonetheless, an established trademark might also go along with outsourcing of labor-abundant activities without transferring advanced technologies.

$S E$ is the service sector share, i.e. the $\log$ output value of the service sector divided by the total output value of the economy. The use and adoption of technologies requires accompanying services, for example for maintenance and readjustment of machinery. Rather than looking at the required skilled workers, this indicator looks at the required services as a prerequisite for running advanced equipment successfully and continuously.

$H T$ is the high-tech industry share, i.e. the $\log$ output value of high-tech manufacturing industries ${ }^{9}$ divided by the total manufacturing industry output value. The weight of the high-tech industry in the economy is another indicator for preexisting technologies and technological capabilities that ease the adoption of new technologies. It is more specific and technology-oriented than the general service sector share, which captures various services that may or may not be relevant in the technological context.

\footnotetext{
${ }^{9}$ Chemicals and Chemical Products; Machinery, Nec; Electrical and Optical Equipment; Transport Equipment; following the Eurostat classification of high-tech manufacturing sectors
} 
The remaining parameters in the equation are the following: $\varsigma$ is the overall constant. $\sigma$ denotes individual effects, this means $\{s r j\}$-triples. $\theta$ denotes time-specific effects. $\epsilon$ is the residual. This specification hence represents the common within-estimator for panel data.

In the first regression, we include all determinants of the absorptive capacity (in logs) subsumed under $[X]$ at the same time, but no interaction terms. In the subsequent regressions, we include only one determinant (in $\log \mathrm{s}$ ) and its multiplicative interaction (in $\log s$ ) with the import rate $I M$ (in $\log s$ ) at the same time. The latter specification strictly avoids collinearity between determinants of absorptive capacity. An $F$-test for the use of individual effects versus a pooled regression opts for the use of individual effects. The Hausman test for random- versus fixed-effects opts for the use of fixed-effects.

\section{Data}

This section details our data and their sources.

We use the novel WIOD database throughout the analysis (cf. Dietzenbacher et al., 2013). The WIOD project has been funded by the European Commission, Directorate General Research, as part of the $7^{\text {th }}$ Framework Programme, Theme 8: Socio-Economic Sciences and Humanities. WIOD has been available for the public since April 2012. ${ }^{10} \mathrm{It}$ is to our knowledge the first database that provides bilateral and bisectoral input-output relations and various socio-economic and environmental indicators for a sequence of years within one consistent data set. We use data for 31 source and eight recipient countries, 35 source sectors and one recipient (investment good) sector and 15 years, 1995 to 2009. This results in about 85,000 observations. Within the WIOD database, we take data on imports of investment goods and domestically produced investment goods from the World Input-Output Tables (WIOT). The service sector share and the high-tech industry share are also computed from the WIOT data. We take data on working hours, output, highskilled labor shares ${ }^{11}$ and price indices used to deflate variables from the Socioeconomic Accounts (SEAs) within WIOD.

The remaining determinants of absorptive capacity are taken from the following data sources: the tertiary education rate, telephone line and internet access rate, the scientific article, patent and trademark rate stem from the World Development Indicators (WDI,

\footnotetext{
${ }^{10}$ Timmer, M.P. (2012, ed.), The World Input-Output Database (WIOD): Contents, Sources and Methods, available at http://www.wiod.org/database/.

${ }^{11}$ High-skilled labor means first and second stage of tertiary education (1997 ISCED levels 5 and 6).
} 
$2012^{12}$ published by The World Bank). Our indicators for economic freedom and civil rights are the Freedom House index ${ }^{13}$ and the Index of Economic Freedom ${ }^{14}$.

For the regressions, we compute the data in three-year moving averages to smoothen them and to mitigate outlier impacts and to address possibly endogeneity issues (caused by external shocks that affect several variables simultaneously). For the regressions, we also compute the data in logs as derived in the previous section. This results in comparable magnitudes of the estimated coefficients.

Table 1 in the Appendix reports descriptive statistics (without logs or moving averages) for all variables. The correlation matrix in Table 2 in the Appendix (with logs and three-year moving averages) shows that most of the determinants of absorptive capacity have a relatively low correlation with each other. ${ }^{15}$ We use them simultaneously as regressors within the first regression, but independently in the remaining regressions. The correlations among the interaction terms (of the determinants of absorptive capacity and the import rate) with each other (not shown in the table) are high. We therefore include only one determinant and the corresponding interaction term at once in the remaining regressions. We ensure stationarity of all data by applying unit root tests for panel data (Fisher-type Augmented Dickey Fuller test based on Dickey and Fuller, 1979, and ImPesaran-Shin, 2003, test). Thanks to the use of labor intensity in relative South-North form, the labor intensity data are stationary as the other data are. We observe negative values of the growth rate of relative labor intensity in almost $60 \%$ of the observations, which implies South-North convergence in labor intensity in these cases.

Figure $1(\mathrm{a}-\mathrm{k})$ in the Appendix plots the determinants of absorptive capacity in the cross section of the eight 'Southern' emerging countries in our sample as averages over the years 1995 to 2009. While some countries perform relatively similar in all determinants of absorptive capacity, other countries differ a lot between the categories. Bulgaria, e.g., exhibits rather high values in all categories (except in the high-tech industry share). Likewise, Brazil and Mexico show a tendency towards medium to high values in all categories. On the contrary, the values from China and Russia range from the highest to the lowest ranking across different determinants. Russia, e.g., exhibits the highest values in tertiary

\footnotetext{
${ }^{12}$ http: //databank. worldbank.org/data/home.aspx.

${ }^{13} \mathrm{http}$ ://www. freedomhouse. org/report-types/freedom-world.

${ }^{14}$ http://www . heritage.org/index/.

${ }^{15}$ Exceptions are particularly the correlations between the scientific articles rate $S A$ and the telephone rate $T P$, between the patent rate $P A$ and the telephone rate $T P$ and the scientific article rate $S A$, between the trademark rate $T M$ and the tertiary education rate $T E$ and the telephone rate $T P$, between the service sector share $S E$ and the high-skilled labor share $H L$, and between the high-tech industry share $H T$ and the domestic investment rate $D I$.
} 
education, scientific articles, and patent applications, whereas it has very low values in the Freedom House index, the Economic Freedom index, and high-tech industry share. China exhibits the highest value in the high-tech industry share, but the lowest values in the categories high-skilled labor share, Freedom House index and the service sector share.

Figure 1 (l) depicts the average ${ }^{16}$ growth rate of relative labor intensity for the eight emerging countries within the time frame 1995 to 2009. South-North convergence of labor productivity is indicated by negative growth rates of relative labor intensity. The figure reveals negative growth rates for Bulgaria, China, India, Romania and Russia. It reveals, on the contrary, positive growth rates for Brazil, Indonesia and Mexico. Positive growth rates indicate that these countries have fallen behind compared to the industrialized countries within the time frame. We detect the highest negative growth rate and hence the strongest catching up behavior for China, and the second highest, but much lower negative growth rate for India.

\section{Results}

This section explains our regression results.

Our regression results are reported in Table 3 in the Appendix. We use two robust standard error variants which turn out to provide the same significance levels as reported in Table 3: first, the robust or sandwich estimator of variance which is robust to some types of misspecification and heteroscedasticity as long as the observations are independent. Second, we cluster cross-sectional panels. As a consequence, observations are required to be independent between clusters (groups) but not necessarily within clusters. Thus, autocorrelation is taken into account (within clusters). Though, the choice of the first or second variant does not affect the results. The first three and the last time- or yearspecific effects are dropped because of collinearity. Note that the $d \log -\log$ specification allows us to compare the estimated coefficients regarding their magnitudes similar to elasticities. The absolute status quo importance of each determinant for an economy can be different though: a determinant with an inelastic additional impact can nevertheless be an important productivity determinant from a historical point of view. A policy priority ranking would need to take the status quo importance into account too.

In regression (1) that includes all determinants of absorptive capacity, but no interaction terms, the investment good import rate has the expected negative sign, whereas

\footnotetext{
${ }^{16}$ The average over source countries, source sectors and years.
} 
the domestic investment rate has a positive sign. This confirms the hypothesis that imports of goods are associated with imports of advanced foreign technologies that enhance productivity and thus reduce labor intensity, in contrast to domestically produced goods that have a low technology level. This result however varies in regressions (2) to (12) that include single determinants and their interaction with the investment good import rate.

In regression (1), the Freedom House and the Economic Freedom index, the tertiary education rate, the internet and the telephone rate, the patent rate and the service sector share have the expected negative sign, and they are all statistically significant. This means, they reduce the growth rate of relative labor intensity and thus contribute to South-North convergence of labor intensities. The high-skilled labor share, the scientific article rate, the trademark rate and the high-tech industry share have a positive sign. This means, they increase the growth rate of relative labor intensity. Apparently, these determinants enhance labor-intensive production. For example, the availability of highskilled labor might foster outsourcing of labor-intensive production to developing countries under certain trademarks. Notably, the coefficient of the high-skilled labor share will switch to insignificantly negative in a robustness check which cautions against its positive coefficient. Yet, it surprises that the rate of scientific and technical publications and the high-tech industry share raise relative labor intensity. The latter result is in accordance with Dechezleprêtre et al. (2013) who explain that existing domestic technologies can replace foreign technologies and thus hinder international technology diffusion. Overall, the magnitude of the estimated coefficients is small. Several coefficients are around -0.05 . This means, a $1 \%$ increase in the indicator of absorptive capacity reduces the growth rate of relative labor intensity by 0.05 percentage points. According to the first regression, the service sector share creates the highest labor intensity reducing effect, and the Freedom House index creates the second highest.

The focus of our examination is not on the direct impact of these determinants, but on their interaction with the import rate as scrutinized in regressions (2) to (12). We want to explore whether the various determinants enhance labor productivity spillovers through imports of investment goods. In these regressions, we include only one determinant of absorptive capacity and its interaction term with imports at a time in order to avoid collinearity problems. It turns out that indeed all interaction terms except the interaction term with the trademark rate have the expected negative sign: a better quality of each determinant together with a higher import rate reduces the relative labor intensity to a larger extent and enhances South-North convergence. We perform $F$-tests for the null 
hypothesis that the specific indicator of absorptive capacity and its interaction term with the import intensity are jointly zero. The null hypothesis is clearly rejected in all cases. The coefficients of the interaction terms have a small magnitude, though. The Economic Freedom and the service sector share interaction have the highest coefficient of about 0.01. This means, a $1 \%$ increase in the interaction term reduces the growth rate of relative labor intensity by 0.01 percentage points. The Freedom House interaction term has the second highest coefficient, yet not significant in this regression. Yet, this coefficient will turn significantly negative in the robustness checks. Surprisingly, the tertiary education interaction with imports is negative, but statistically not significant. This finding will hold throughout the robustness checks.

Looking at the determinants of absorptive capacity as single regressors in regressions (2) to (12), we find similar results as in regression (1): the high-skilled labor share, the tertiary education rate and the scientific article rate switch their sign in regressions (2), (5) and (8) compared with regression (1). This means, high skills now have the expected negative sign, whereas tertiary education has a counterintuitive positive sign. This latter result will partly be rejected by the robustness checks. The trademark rate and the hightech industry share keep their previous positive sign in regressions (10) and (12). All other determinants reduce the relative labor intensity as expected. The magnitude of these direct effects on relative labor intensity is clearly larger than the magnitude of the interactions with the import rate.

To conclude, our fixed-effects panel estimations overall confirm the hypothesis that the various determinants of absorptive capacity that we inspect interact with investment good imports in such a way that relative labor intensity is reduced (in other words, that labor productivity is augmented).

\section{Robustness}

This section critically discusses our analysis in terms of (1) time lags, (2) endogeneity of regressors, (3) autocorrelation and (4) the exclusion of other determinants of labor productivity.

(1) Technology diffusion processes certainly require time, probably more than one year. Hence, we assume a time lag of three years between importing or domestic investment and the effect on relative labor productivity. In this way, we still capture a relatively short horizon. Because our sample encompasses 15 years, we can hardly capture long-term effects that occur over decades. We also try other time lags and find that the coefficients 
of the determinants of absorptive capacity diminish in most instances for shorter time lags as one would expect. Yet, the choice of appropriate time lags is a critical issue in every analysis of technology diffusion processes, especially at the macro level that encompasses all types of technologies and productivity gains.

The use of time lags also helps us address possible endogeneity of regressors. One could argue that labor productivity is a measure for per capita income and thus the state of economic development. Hence, our measures of absorptive capacity such as education likely depend on the state of economic development and hence on the dependent variable. In this respect, the use of time lags attenuates the likelihood that the dependent variable has an impact on the regressors that are located previously in time. Furthermore, we compute the dependent variable in relative form in terms of a South-North ratio. Thus, the dependent variable describes the relative state of economic development, which again attenuates possible endogeneity.

(2) Nonetheless, we re-estimate our regressions by applying GMM (Generalized Method of Moments) regressions. Since no strictly exogenous determinant of absorptive capacity is available, we use four-period lagged variables as instruments. We particularly want to instrument the indicators of absorptive capacity and the interaction terms of these regressor with the import rate because these are the regressors of main interest. Though, we need to restrict the number of instruments in order to avoid overidentification problems. Hence, we use each four-period lagged indicator of absorptive capacity, each four-period lagged interaction term and the four-period lagged import rate as instruments. ${ }^{17}$ The results are reported in Table 4 in the Appendix. Due to the use of time-lagged variables as instruments, the total number of observations (not reported) becomes slightly smaller than in the previous regressions. The explanatory power expressed as $R^{2}$ values (not reported) is similar as before. We leave out the overall constant without an effect on the results because the constant is captured by the cross-section fixed-effects. We also utilize time fixed-effects as before. The table also reports the results of an endogeneity test ${ }^{18}$ and of the Hansen test for overidentifying restrictions expressed as the $J$-statistic.

The results of the endogeneity test indicate that the instrumented variables - all indicators of absorptive capacity in column (1); the indicator of absorptive capacity and the interaction term with the import rate in columns (2) to (12) - are endogenous in all

\footnotetext{
${ }^{17}$ In regression (1), all determinants of absorptive capacity are instrumented with their four-period lagged counterparts and the four-period lagged import rate.

${ }^{18}$ The endogeneity test is similar to the $C$-statistic (also termed GMM distance test), i.e. it is computed as the difference of two $J$-statistics: one for the equation where the specified regressors are treated as endogenous, and one for the equation where the specified regressors are treated as exogenous.
} 
regressions. ${ }^{19}$ The high test statistics and low $p$-values imply that the null hypothesis that the selected regressors can be treated as exogenous is rejected in all columns.

The $J$-statistics indicate that we use valid instrumental specifications in most of the regressions. In ten out of 12 regressions the $p$-values of the $J$-tests are around ten per cent or higher. Accordingly, we cannot reject the null hypothesis that the specification is valid. The null hypothesis is rejected, though, in regressions (5) and (10) (tertiary education and trademark rate), which cautions against these GMM estimates that yield statistically insignificant coefficients of the interaction terms anyway.

The GMM estimations in general underpin our previous fixed-effects regressions. The signs of the coefficients are confirmed in almost all statistically significant cases. In regression (1), the high-skilled labor share switches its sign from positive to negative (insignificant), whereas the Economic Freedom index (insignificant) and the telephone rate switch from negative to positive. Thus, the previous counterintuitive detrimental effect of skills on relative labor productivity is refuted. The trademark rate is statistically not significant anymore in regression (1). All other determinants have the same sign as before. The magnitudes of the coefficients are overall very similar to their previous magnitudes. The Freedom House index extends its strong significantly negative impact.

In regressions (2) to (12), the signs of the determinants of absorptive capacity used as single regressors are confirmed in almost all cases. The effect of tertiary education is not significant anymore. This outcome rebuts the previous counterintuitive detrimental effect of tertiary education. (Though, this specification is not supported by the $J$-test.) In contrast to the previous regressions, the domestic investment rate has now a negative sign in regressions (6) and (7). The focus of our examination is on the interaction of the indicators of absorptive capacity with the import rate. Backing up our previous main finding, all significant interaction terms have the expected negative sign. Yet, the trademark interaction and the high-tech interaction are not significant anymore.

The magnitude of all coefficients varies only slightly compared with our previous regressions. All significant interaction terms except in regression (3) have a slightly smaller magnitude than in our previous regressions. The interaction term of the high-tech industry share is no longer statistically significant. The impact of the domestic investment rate and most of the determinants of absorptive capacity increases slightly. The impact of several determinants of absorptive capacity - Economic Freedom Index in (4), internet

\footnotetext{
${ }^{19}$ Additionally, we perform the endogeneity test only on the particular indicator of absorptive capacity in regressions (2) to (12) and come to the same conclusion as in the simultaneous endogeneity test.
} 
rate in (6), trademark rate in (10) and service sector share in (11) - declines. The impact of the import rate declines as well.

(3) The Durbin-Watson statistic indicates positive first-order autocorrelation, $\mathrm{AR}(1)$, of the error terms. Although we use robust (clustered) standard errors in our regressions, we address this issue explicitly. In particular, we check whether the significance levels decline when taking autocorrelation explicitly into account. We apply the Baltagi and $\mathrm{Wu}$ (1999) Feasible Generalized Least Squares (FGLS) estimator (xtregar in 'Stata'). Time- and cross-section fixed-effects are in this case left out. The results are reported in Table 5 in the Appendix. Overall, they corroborate our main panel estimations, especially the statistical significance of the estimated coefficients. For comparison, we also apply the Prais-Winsten estimator as discussed in Judge et al. (1985) (prais in 'Stata'). Like the Baltagi and Wu (1999) estimator, this Generalized Least Squares (GLS) estimator is designed for linear regression models in which the error terms follow a first-order autoregressive process. In the Prais-Winsten estimations, we exclude any fixed- or random-effects. The Prais-Winsten estimations in general confirm the Baltagi and $\mathrm{Wu}(1999)$ estimations and are hence not reported. The transformed Durbin-Watson statistics (around 1.6) depict that autocorrelation has been successfully mitigated.

The following aspects are worth mentioning regarding the results reported in Table 5. Many coefficients have a smaller magnitude in the FGLS regressions than in the main regressions. The surprising positive coefficient of the high-tech industry share in column (12) has switched to negative for the single regressor as well as for the interaction with imports. This means, according to the new regressions in Table 5, a larger high-tech industry share reduces relative labor productivity directly and via imports. The hightech coefficient in column (1) remains positive, though. Instead, the coefficient of the high-skilled labor share has counterintuitively switched to positive in the new regression (2). The previously positive coefficient of the trademark-import interaction in column (10) has now turned insignificant.

(4) In addition, one can imagine other determinants of labor productivity like labor taxes and labor market regulation that we do not include. - The inclusion of wages would be problematic because wages depend on labor productivity, the dependent variable. The first reason for not including them is unavailability of data for our country and time sample. The second reason is that such determinants are not the focus of our analysis. This also applies to foreign direct investment (FDI), which is viewed as another channel of technology spillovers. Regarding FDI, we would particularly face the problem that the 
data are not available with a bilateral and bisectoral resolution as our trade data. Thus, we use time fixed-effects for each year and cross-sectional fixed-effects that are specific for source and recipient countries as well as source sectors. These fixed-effects are expected to capture most of the unobserved heterogeneity in the sample.

To explore the impact of the fixed-effects, we also run GMM regressions without any fixed-effects. The results show that the impact of the indicators of absorptive capacity and their interactions with the import rate become one order of magnitude larger than in the regressions with fixed-effects. The impact of the import rate even goes up between two to three orders of magnitude. We suppose, however, that this hinges upon the correlation of absorptive capacity with other unobserved country-specific factors so that the regressions without fixed-effects do not disentangle the impact of absorptive capacity from the impact of other determinants. Notwithstanding, these results indicate that the low magnitude of the effects that we find in our previous regressions defines a lower bound of the magnitude of the effects under scrutiny.

To conclude, the GMM and FGLS regressions overall approve our previous panel estimations and remedy the few counterintuitive results of the previous estimations.

\section{Policy}

Based on these estimates, we conduct the following policy thought experiment: imagine that policy measures are successful in augmenting all determinants of absorptive capacity with a significantly negative coefficient in the emerging economies to the maximum level found in the industrialized countries. For this purpose, we include the significantly negative coefficients of Table 3, column one that includes all determinants simultaneously: the Freedom House index, the Economic Freedom index, the internet and the telephone rate, the patent rate and the service sector share. We exclude the tertiary education rate, because it is significantly positive in column five in Table 3 and Table 5 (the FGLS robustness check) and insignificant in Table 4 (the GMM robustness check). Taking the results reported in Table 3 in column one at face value, the resulting direct reduction of relative Southern labor intensity growth will be about 127 percentage points. ${ }^{20}$ Taking into account the three-year time lag of international technology diffusion underlying our

\footnotetext{
${ }^{20}$ We proceed in the following way: we compute the average value across the emerging countries for each determinant of absorptive capacity. We also identify the maximum value in the sample, in general found among the industrialized countries, for each determinant. The relative difference between these two values for each determinant yields the necessary improvement of each determinant. We then multiply this relative difference by the estimated coefficient of each determinant. We compute each impact on the growth rate of relative labor intensity and add the impacts up.
} 
estimations, this result implies that full South-North convergence would be reached within a four-year time frame. This effect appears huge. Yet, the underlying assumption that the average emerging economy of our sample is able to lift all determinants of absorptive capacity to the maximum level in the world immediately is very optimistic. In reality, the improvement of absorptive capacity would be a graduate long-term process so that South-North convergence would require a long time horizon, too.

In comparison to this strong direct, trade-independent effects, the productivity gains achievable through the trade channel are much smaller. Let us assume the same immediate improvement of the same determinants of absorptive capacity as above. When we add up the coefficients for the interaction of each determinant with the import intensity in Table 3, columns three to eleven (imports and everything else equal), the resulting indirect enhancement of relative Southern labor productivity through the trade channel will be about four percentage points per year. Recalling that we measure all effects with a time lag of three years, we gain a time horizon of 20 years for halving the relative Southern labor intensity solely through the trade channel.

To conclude, we find a strong direct, trade-independent South-North convergence effect through the improvement of the Southern absorptive capacity, represented by the joint augmentation of various determinants. On the contrary, the indirect, trade-related convergence effect, which is the focus of our analysis, is much smaller. Even with a very optimistic assumption about the improvement of absorptive capacity, we require a couple of decades to halve the gap between Southern and Northern labor intensities.

\section{Conclusion}

Our regressions, including an extended number of determinants of absorptive capacity (the ability to absorb foreign technologies successfully), show that imported investment goods bring about productivity gains for 'Southern' emerging economies. These productivity gains result in South-North convergence of labor intensities. Yet, this finding varies in some estimations such that imports worsen the Southern labor intensity relative to the North. As a robust finding, we show that the joint effect of investment good imports and most determinants of absorptive capacity results in labor productivity gains and thus South-North convergence.

Firms in industrialized countries demur that trade-related knowledge spillovers could enhance competition with firms in emerging economies, especially when these economies make progress in terms of absorptive capacity. It follows from the results that this demur is 
only rudimentarily justified: the estimated trade-related effects have a small magnitude so that they require a time horizon of some decades to become apparent. In some regressions, trade in investment goods itself even lowers the labor productivity of emerging economies; outsourcing of labor-intensive activities to emerging low-wage countries is one possible explanation for this result.

When policy makers aim to support knowledge (technology) diffusion to emerging or developing countries, relying solely on international markets will according to our results have a weak effect. It is not sufficient for achieving a momentous medium-term effect to select one determinant of absorptive capacity such as internet access, either. It is more promising to invest in a variety of the determinants identified above in order to achieve an ample joint effect. If a ranking of determinants is requisite in terms of investment priority, our results suggest the following considerations ordered by the magnitude of the estimated coefficients in our $d \log -\log$ specification: (1) Freedom of economic activity and political and civil rights are the most important general prerequisite for successful economic activity and hence for successfully making use of international technology spillovers. Although only property rights are part of the indexes utilized in our analysis, this result could be interpreted in that way that stronger intellectual property rights enhance international technology diffusion. This result is not undisputed, though (cf. Branstetter et al., 2006; Lerner, 2009), since laxer intellectual property rights ease imitation and would give developing countries essential access to advanced technologies and products such as medical products or environmentally friendly technologies. (2) The service sector emerges as an almost equally important and more specific factor for international technology diffusion, presumably because it provides services like technical consulting and maintenance of devices that are necessary to utilize technologies. (3) High skills of workers improve the ability to utilize, adopt, develop and imitate new technologies. (4) Basic research and applied research as well as the existing high-tech sector provide the knowledge base to build on for understanding and assimilating new technologies. Notwithstanding, in accordance with Dechezleprêtre et al. (2013), our results suggest that the role of existing domestic technologies is ambiguous: they may enhance the absorbtion of new technologies, but also substitute foreign technologies and thus hinder the absorption of foreign technologies. Notably, trademarks alone are not sufficient to guarantee technology spillovers. On the contrary, they may indicate outsourcing of labor intensive production. (5) Access to modern telecommunication opens up a whole universe of information including technology-oriented knowledge. Communication systems enable scientific and practical 
information flows that enhance technology diffusion. Interestingly, we do not detect that tertiary education, a common determinant of technical progress in the literature, creates labor productivity gains through the interaction with imports, but merely as a separate determinant (together with the other determinants of absorptive capacity). The latter result is in accordance with the literature (going back to Nelson and Phelps, 1966, as summarized in section 2); whereas the former indicates that the importance of education for productivity growth does not automatically transfer to technology diffusion via imports. Furthermore, labor productivity gains via tertiary education as a separate determinant are not a robust finding across our regressions, which is in line with the dispute over the importance of education for productivity (cf. Pritchett, 2001).

Policy makers also may consider the time lag between the change in absorptive capacity and its effect on growth. We use three-year lags in our analysis and find that shorter time lags dilute this effects. In general, policy makers may consider that the effects under scrutiny require a substantial time frame to become effective: even when policy makers were able to lift the absorptive capacity of an average Southern economy immediately to the maximum level in the world, halving the South-North gap in labor intensities would require a couple of decades if it were solely achieved through the trade channel. The direct, trade-independent effect of the absorptive capacity on the reduction in Southern labor intensity is substantially higher. This implies that trade policy clearly has a smaller impact on productivity than policies that target the drivers of productivity growth discussed above directly - independent of international trade.

Future research could extend the scope of the analysis to other countries and determinants of absorptive capacity as soon as the required data become available.

\section{Acknowledgment}

This work was supported by the state of Baden-Württemberg within the programme Strengthening Efficiency and Competitiveness in the European Knowledge Economies (SEEK). We are very grateful to Susanne Becker for her great help. We also thank Simon Koesler, Florens Flues, Sourafel Girma, Carolyn Fischer, Michael Schymura, Andreas Löschel, Taran Fæn and Ebru Voyvoda. 


\section{References}

Abramowitz, M. (1986). Catching-up, forging ahead and falling behind. Journal of Economic History, 385-406.

Augier, P., O. Cadot and M. Dovis (2013). Imports and TFP at the firm level: the role of absorptive capacity. Canadian Journal of Economics 46(3), 956-981.

Baltagi, B.H. and P.X. Wu (1999). Unequally spaced panel data regressions with AR(1) disturbances. Econometric Theory 15, 814-823.

Benhabib, J. and M. Spiegel (2005). Human capital and technology diffusion. In Handbook of economic growth, ed. P. Aghion and S. Durlauf, 935-966. North-Holland: Elsevier.

Borensztein, E. J. de Gregorio and J.W. Lee (1998). How does foreign direct investment affect economic growth? Journal of International Economics 45(1), 115-135.

Branstetter, L.G., R. Fisman, and C.F. Foley (2006). Do Stronger Intellectual Property Rights Increase International Technology Transfer? Empirical Evidence from US FirmLevel Panel Data. Quarterly Journal of Economics 121(1), 321-49.

Carraro, C. and E. De Cian (2013). Factor-augmenting technical change: an empirical assessment. Environmental Modeling and Assessment 18(1), 13-26.

Ciruelos, A. and M. Wang (2005). International technology diffusion: Effects of trade and FDI. Atlantic Economic Journal 33(4), 437-449.

Dickey, D.A. and Fuller, W.A. (1979). Distribution of the Estimators for Autoregressive Time Series with a Unit Root. Journal of the American Statistical Association, 74, 427-431.

Coe D.T. and E. Helpman (1995). International R\&D Spillovers. European Economic Review 39(5), 859-887.

Coe D.T., E. Helpman and A.W. Hoffmaister (1997). North-South R\&D Spillovers. Economic Journal 107(440), 134-149.

Coe D.T., E. Helpman and A.W. Hoffmaister (2009). International R\&D Spillovers and Institutions. European Economic Review 53(7), 723-741.

Crespo-Cuaresma, J., Foster, N. and J. Scharler (2008). Barriers to Technology Adoption, International R\&D Spillovers and Growth. Economics Bulletin 15, 1-7.

Dechezleprêtre, A., M. Glachant and Y. Ménière (2013). What Drives the International Transfer of Climate Change Mitigation Technologies? Empirical Evidence from Patent Data. Environmental and Resource Economics 54, 161-178.

Dietzenbacher, E., B. Los, R. Stehrer, M. Timmer and G. de Vries (2013). The Construction of World Input-Output Tables in the WIOD Project. Economic Systems Research 25(1), 71-98.

Eaton, J. and S. Kortum (1996). Trade in ideas: Patenting and productivity in the OECD. Journal of International Economics 40(3-4), 251-278. 
Findlay, R. (1978). Relative backwardness, direct foreign investment, and the transfer of technology: a simple dynamic model. Quarterly Journal of Economics 92(1), 1-16.

Girma, S. (2005). Absorptive capacity and productivity spillovers from FDI: a threshold regression analysis. Oxford Bulletin of Economics and Statistics 67(3), 281-306.

Griffith, R., S. Redding and J. van Reenen (2004). Mapping the two faces of R\&D: productivity growth in a panel of OECD industries. Review of Economics and Statistics 86(4), 883-895.

Hoekman, B. and B.S. Javorcik, eds. (2006). Global integration \& technology transfer. Washington, D.C., The World Bank.

Im, K.S., Pesaran, M.H. and Shin, Y. (2003). Testing for unit roots in heterogeneous panels. Journal of Econometrics, 115, 53-74.

Judge, G.G., W.E. Griffiths, R.C. Hill, H. Lütkepohl and T.-C. Lee (1985). The Theory and Practice of Econometrics. Wiley, $2^{\text {nd }}$ ed., New York, USA.

Keller, W. (2004). International technology diffusion. Journal of Economic Literature, American Economic Association 42(3), 752-782.

Kneller, M. (2005). Frontier technology, absorptive capacity and distance. Oxford Bulletin of Economics and Statistics 67(1), 1-23.

Lai, M., S. Peng and Q. Bao (2006). Technology spillovers, absorptive capacity and economic growth. China Economic Review 17, 300-320.

Lerner, J. (2009). The Empirical Impact of Intellectual Property Rights on Innovation: Puzzles and Clues. American Economic Review: Papers and Proceedings 99(2), 343-348.

Mazumdar, J. (2001). Imported Machinery and Growth in LDCs. Journal of Development Economics 65(1), 209-224.

Nelson, R. and E. Phelps (1966). Investment in humans, technological diffusion, and economic growth. American Economic Review: Papers and Proceedings 61, 69-75.

Perkins, R. and E. Neumayer (2012). Do recipient country characteristics affect international spillovers of CO2-efficiency via trade and foreign direct investment? Climatic Change 112(2), 469-491.

Saggi, K. (2002). Trade, foreign direct investment, and international technology transfer: a survey. World Bank Research Observer 17(2), 191-235.

\section{Appendix}




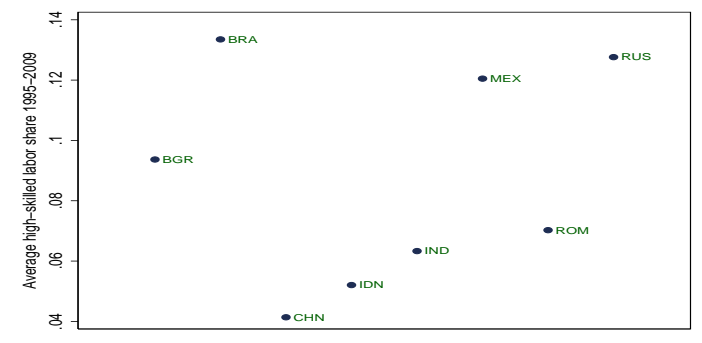

(a)

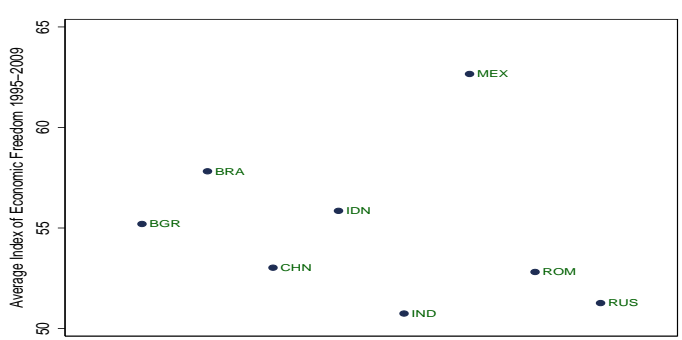

(c)

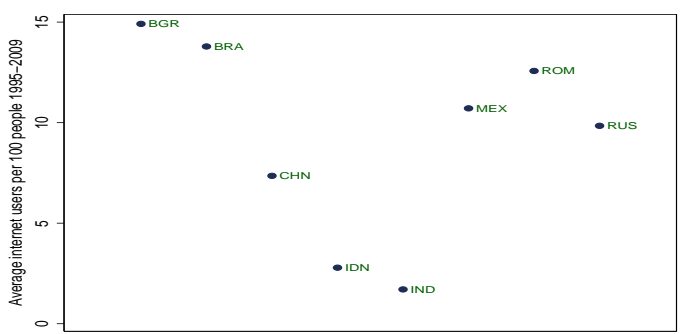

(e)

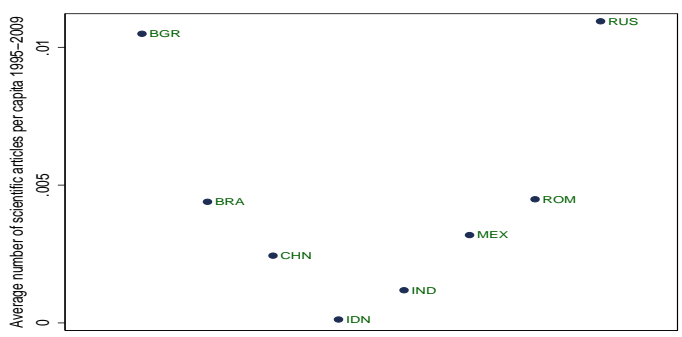

(g)

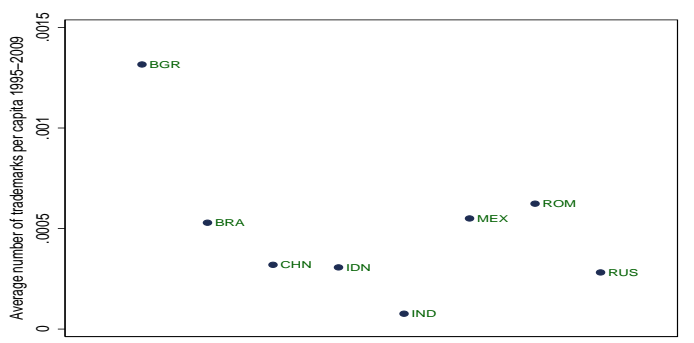

(i)

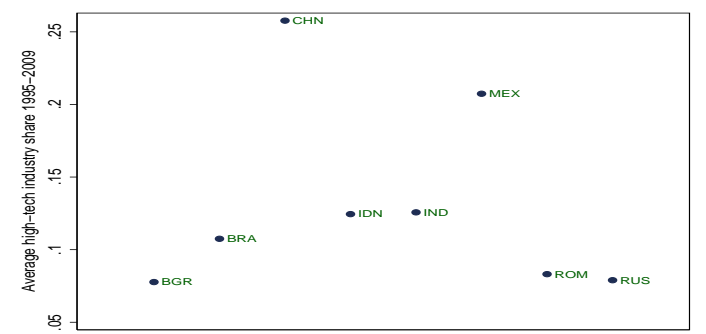

$(\mathrm{k})$

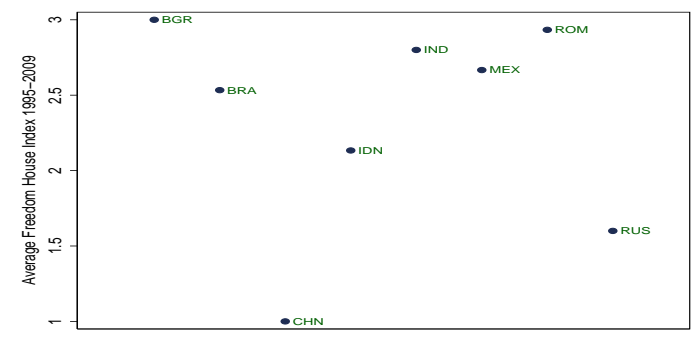

(b)

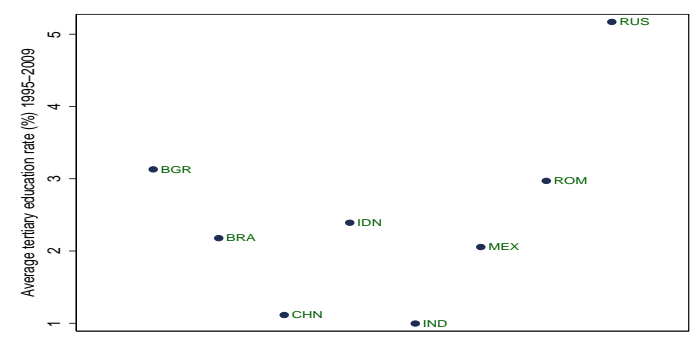

(d)

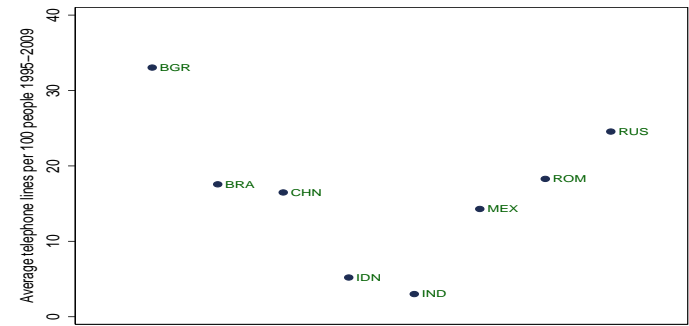

(f)

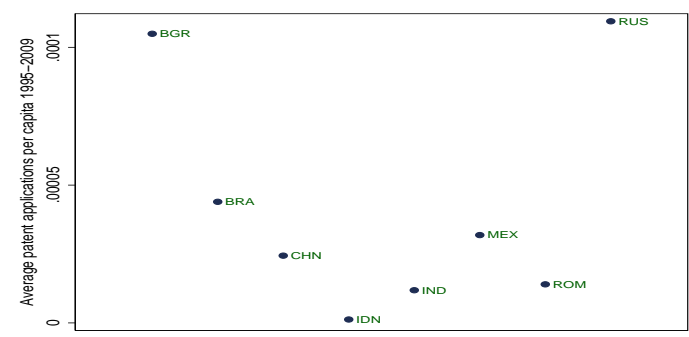

(h)

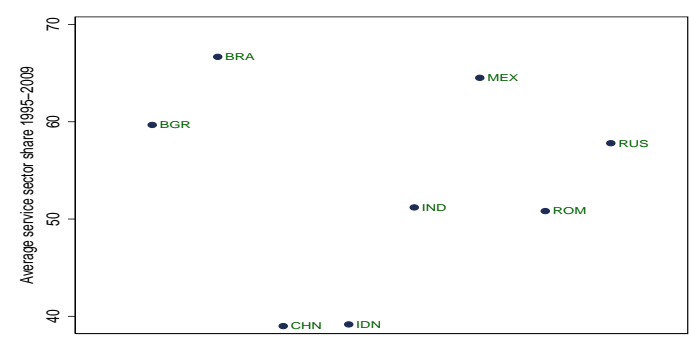

(j)

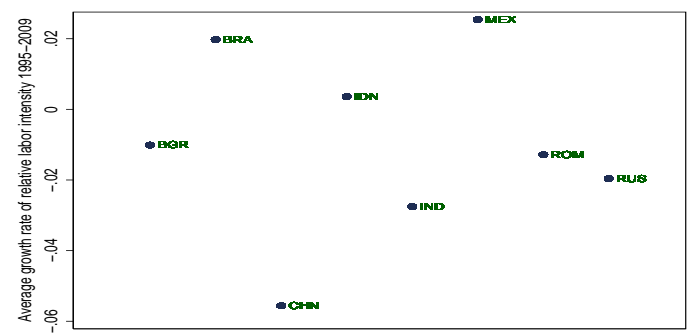

(1)

Figure 1: Determinants of absorptive capacity, BGR $=$ Bulgaria, $\mathrm{BRA}=$ Brazil, $\mathrm{CHN}=$ China, IDN $=$ Indonesia, IND $=$ India, $\mathrm{MEX}=$ Mexico, $\mathrm{ROM}=$ Romania, and RUS $=$ Russia. 


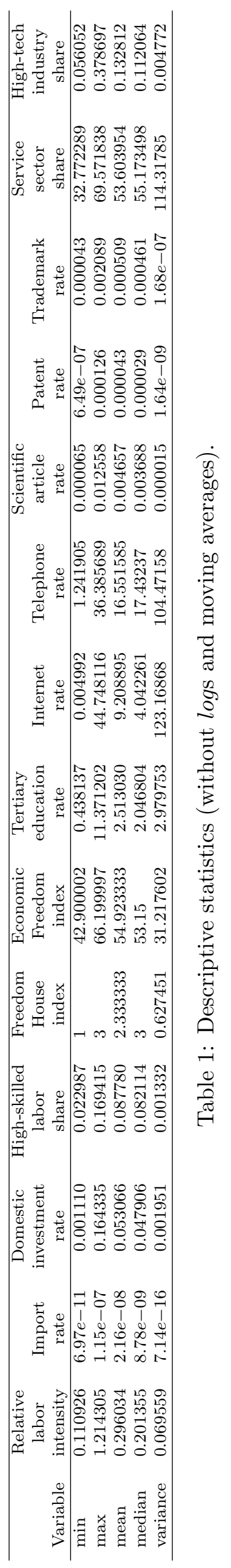




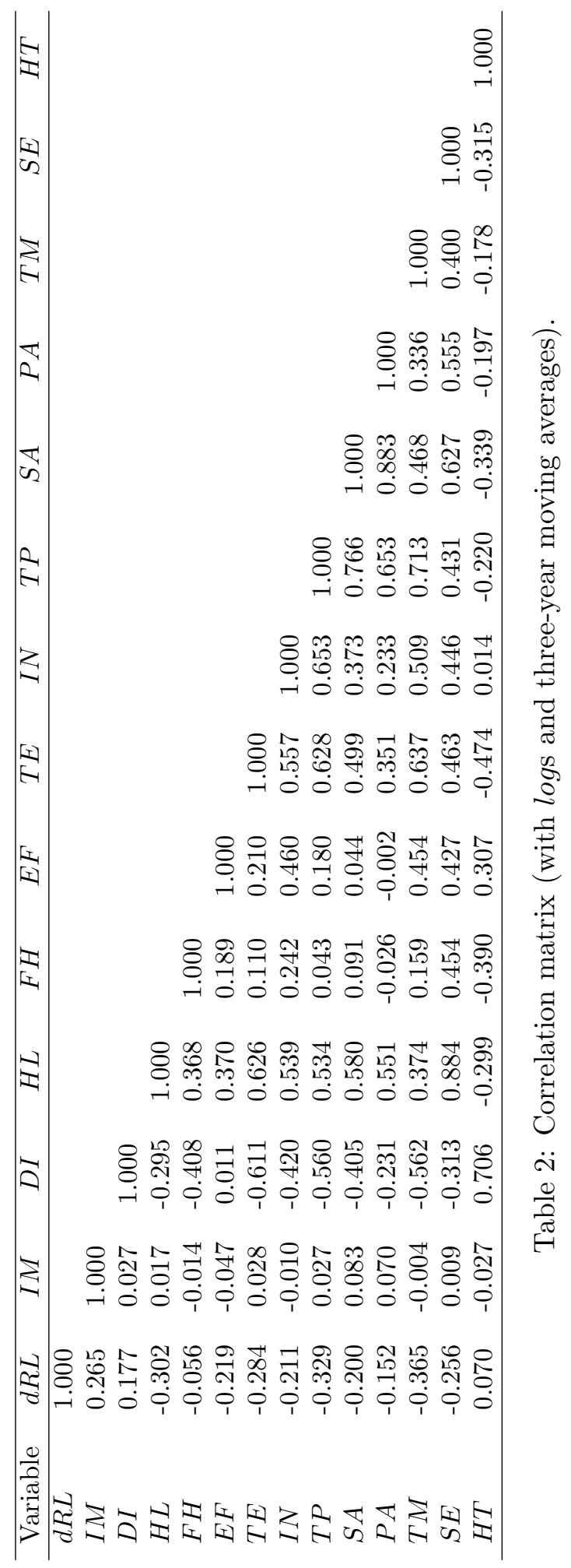




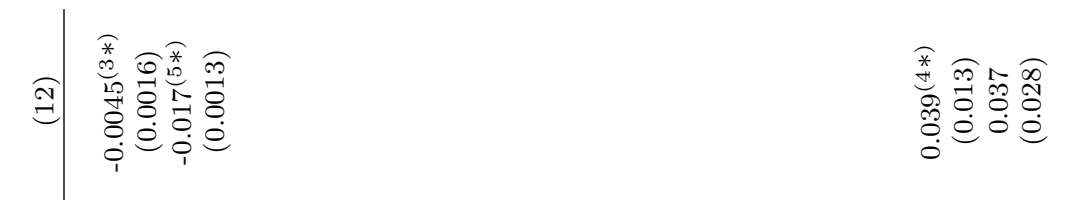

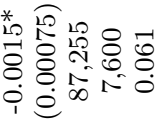

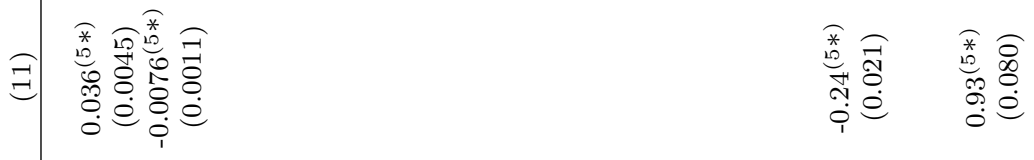

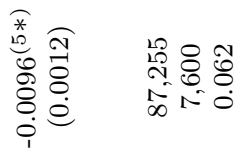

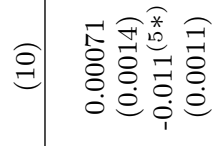

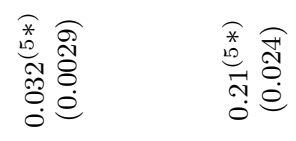

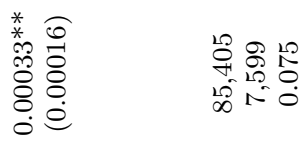

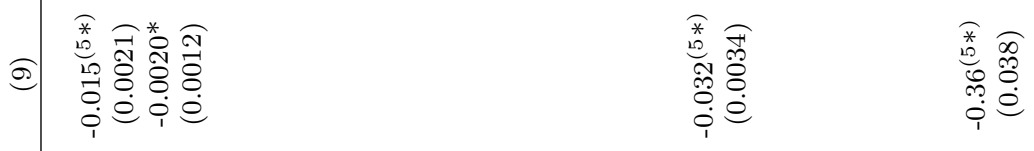

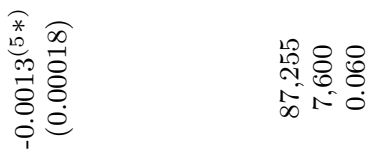

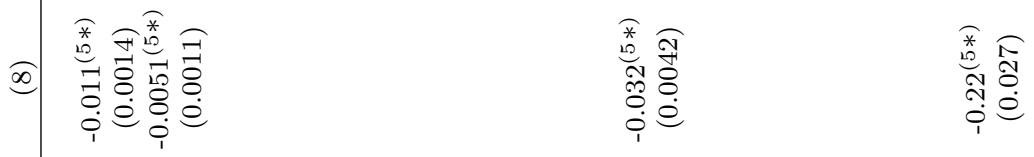

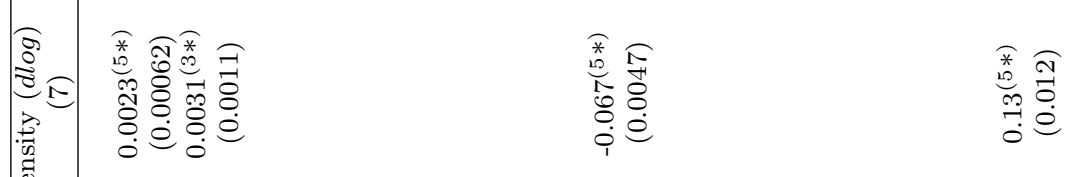
咅獣

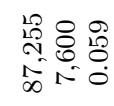

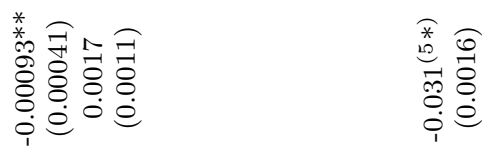

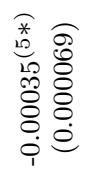

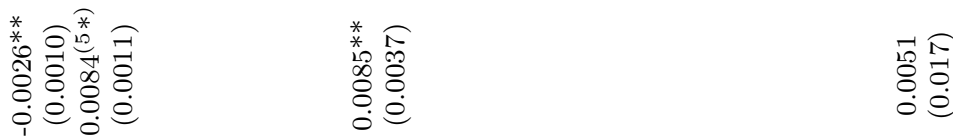

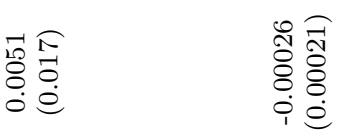
高
嗷

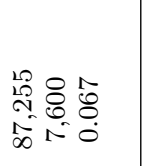

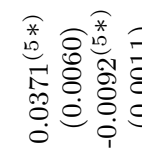

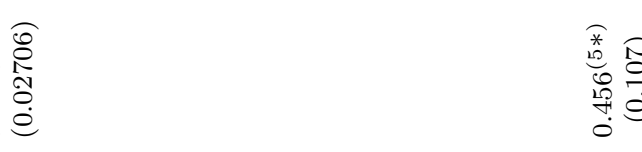

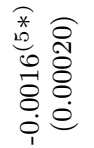

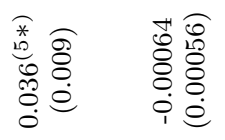
管得

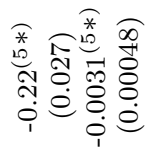
喜奥

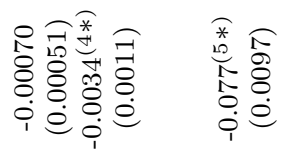

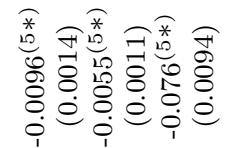

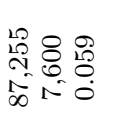

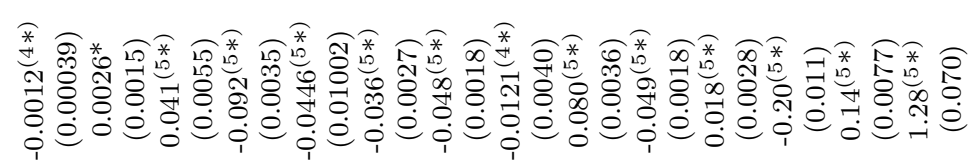

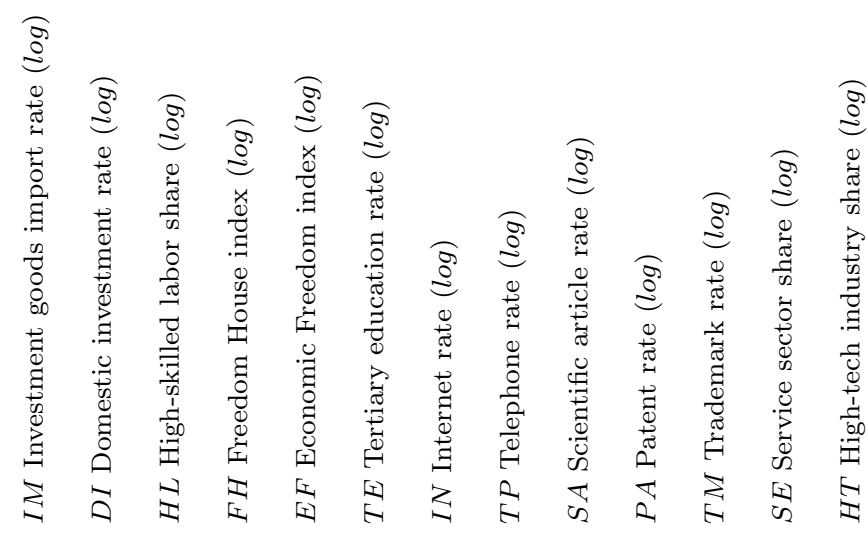

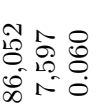

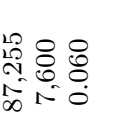

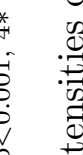
范 


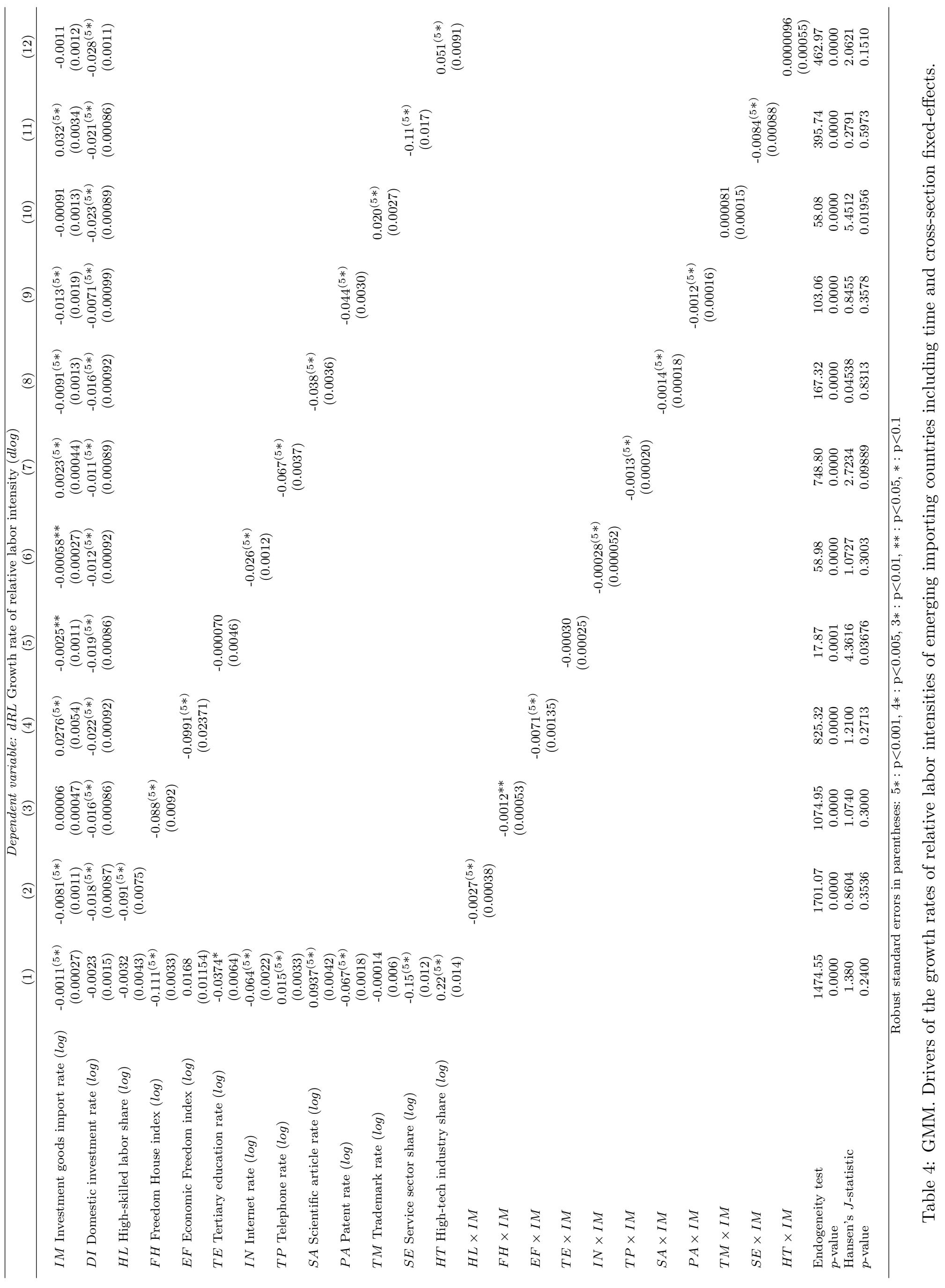


